\section{DEMONSTRATIONS OF PHYSICAL SIGNS IN CLINICAL SURGERY}

By Hamilton Bailey, F.R.C.S., F.A.C.S. John Wright and Sons, Bristol. 1948. I I th Edition, in four parts. Part I. Pp. xii and 100. 178 illustrations. Price 8 s. 6 d. per part.

Hamilton Bailey's admirable illustrated guide for the surgical dresser appears in its $I$ Ith edition and promises to be even fuller and better supplied with coloured photographs than before. We say promised, because it has been found necessary to issue it in four paper covered parts to circumvent some of the present day delays in printing and binding, and so far only the first part has been prepared.

This book presents the best collection of clinical photographs that is published today and, together with the simple text, forms the ideal introduction for a student to the physical signs of surgery. It would be a pity if the book grew any larger as it already looks as if the completed work will be quite bulky to carry about. A pleasant feature is the inclusion of footnotes describing the originators of the various eponymous signs which are such a feature of surgical and medical diagnosis. The price of $8 \mathrm{~s}$. $6 \mathrm{~d}$., which is asked for each of the four parts, represents excellent value when one considers the number of coloured blocks which have been used in this publication. However the total cost of the finished work which will be $34 \mathrm{~s}$. is rather high, since it will mainly be bought by medical students.

The undergraduate student of surgery and especially the examination candidate owes a considerable debt to Hamilton Bailey, who has probably done more than any other single author to lighten his burden.

\section{S.F.T}

\section{HYGIENE}

By J. R. Currie, M.A., M.D., Ll.D., D.P.H., F.R.C.P.(Edin.), and A. G. MEarNs, M.D., B.Sc., D.P.H., F.R.S.(Edin). E. \& S. Livingstone Ltd. 1948. 3rd Edition. Pages $724+$ xx. Price 35s.

The excellence of this book lies in the broad scope with which it deals with the history, science, art and probable developments of hygiene and social medicine. It is an eminently readable compendium of the whole study of healthy living. The preface to the first edition states an intention to cater for students of medicine and those engaged in general practice. This third edition notes a change to cover the course for the examinations in Public Health and to serve as a book of reference for Officers of Health Departments. To the reviewer it seems that the original conception was admirably achieved, and the result of the endeavour to enlarge the circle of readers is equally successful. It is impossible to combine the needs of all without presenting more than the undergraduate may require. From this point of view it is hoped that medical students will not be deterred by the mass of in- formation the book contains, but will continue, with judicious selection, to use it as their introduction to the subject. It is doubtful if they will find elsewhere any other guide so comprehensive. July $5^{\text {th }}$, I948, has made some of the administrative details obsolete, but wherever possible the authors have given forecasts of the new legislation. This minor defect is common to all current textbooks of social medicine and, as far as this work is concerned, capable of remedy with little alteration.

Meanwhile, the work can be recommended without reservation for students as a complete guide to the principles and practice of hygiene, and for all Health Department Officers as a comprehensive reference covering the art and theory on which their daily routine is founded.

As an example of the technique of book production, this volume achieves the usual standard expected of the House of Livingstone.

\section{S.L.W.}

\section{TREATMENT BY MANIPULATION IN GENERAL AND CONSULTING PRACTICE}

By A. G. Timbrell-Fisher, M.C., F.R.C.S.(Eng.).

Fifth Edition. H. K. Lewis and Co. London. 1948. Pp. ix + 275. I 26 illustrations. 25s. net.

This edition of Mr. Timbrell-Fisher's wellknown book appears twenty-three years after the first publication. Although it is only a few years since it was revised, he has rewritten a good deal, made valuable additions, especially in the treatment of deformities of rheumatic disease and has added 45 new illustrations.

This book is of great value, in that it contains a mass of information on common conditions, which does not appear in textbooks. Many of these conditions are well recognized, but often thought to be in the class of physical ailments which will not respond to physical treatment. Many have been treated with drugs or phsyiotherapy with little benefit; the author describes the practical method of manipulation which is suitable for each, and illustrate. the method of examination and technique of treatment. His approach to the subject enables the reader to visualize the advance in this line of treatment and appreciate that it is based on scientific principles.

Stress is laid on contraindications as well as indications for manipulation. The value of rest in the one case, and of exercise in the other is enunciated. The author's interest in those crippled with rheumatic disease is well known, so that the methods he advises for dealing with deformity are advocated after great experience. He records the treatment enabling some bedridden patients to walk again.

This book is not an A.B.C. of how to manipulate a stiff joint or relieve a chronic sprain, but a clearly written, well illustrated and up-to-date volume full of information on every aspect of a subject of interest to many branches of the medical profession.

St.J.D.B. 